
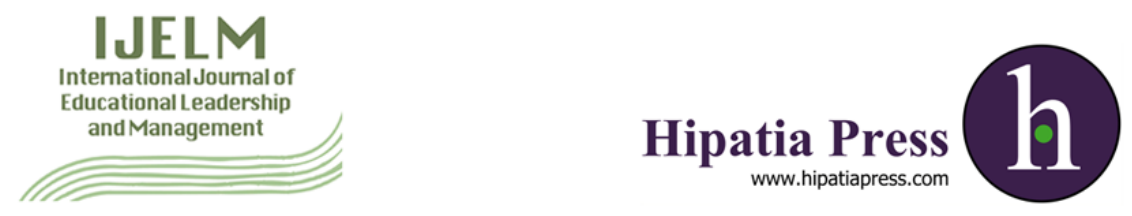

Instructions for authors, subscriptions and further details:

http://ijelm.hipatiapress.com

\title{
Ed.D. Programs as Incubators for Social Justice Leadership.
}

\section{Carmen Elboj ${ }^{1}$}

1) Universidad de Zaragoza

Date of publication: January $16^{\text {th }}, 2018$

Edition period: January 2018-July 2018

To cite this article: Elboj, C (2018). Ed.D. Programs as Incubators for Social Justice Leadership. [Review of the book: Ed.D. Programs as Incubators for Social Justice Leadership]. IJELM, 6(1), 96-97. doi: 10.17853/ijelm.2017.3192

To link this article: http://dx.doi.org/10.17583/ijelm.2017.3192

\section{PLEASE SCROLL DOWN FOR ARTICLE}

The terms and conditions of use are related to the Open Journal System and to Creative Commons Attribution License (CC-BY). 


\section{Review}

Ellis, A. (2016). Ed.D. Programs as Incubators for Social Justice Leadership. Rotterdam: Sense Publishers. ISBN: 2365-6263

través de sus doce capítulos con autores y autoras de muy diversos contextos, este libro incluye aportaciones vinculadas a los programas educativos que promueven el liderazgo para la justicia social. Las diferentes contribuciones abordan temáticas como el uso de la nueva teoría de liderazgo educativo para promover la justicia social, la definición de problemas para facilitar el cambio o la necesidad de implementar una pedagogía crítica para desarrollar el liderazgo vinculado a la equidad. Además, se abordan temáticas muy concretas sobre liderazgo y justicia social, como por ejemplo el desarrollo de un contexto en el que se ayude a líderes urbanos a minimizar la sobrerepresentación de hombres afroamericanos en la educación especial.

Los debates sobre justicia social y liderazgo que se presentan ponen de manifiesto la necesidad de profundizar desde los programas educativos en fortalecer esa vinculación. De este modo, tal y como se argumenta en el tercer capítulo dedicado a la preparación del liderazgo educativo que transforma la práctica, el debate sobre la justicia social está estrechamente vinculado a los principios de los líderes escolares. En ese sentido, se buscan contextos de aprendizaje que incluyan no solo la dimensión académica de aprendizaje sino 
también su dimensión social y moral. Precisamente, esa búsqueda está en línea con los debates internacionales en educación y liderazgo.

Carmen Elboj, Universidad de Zaragoza 